histological techniques. The 'beta' zone contains slightly more lipoid and rather more vitamin $\mathrm{C}$, but these materials and the fats, etc., are concentrated chiefly in a very thin peripheral cortical rim-the 'alpha' zone.

The 'beta' zone, and more rarely the 'delta' zone, may be stained bright yellow due to the diffusion through the cytoplasm of a lipochrome pigment, presumably a carotene. The occurrence of this pigment bears no relation to the reproductive cycle. At times, masses of lipochrome may be seen in the vascular clefts of the cortex and in the medullary sinuses. The latter are sometimes crammed with these masses. The cells of the zona reticularis are invariably packed with lipochrome in the form of globules of various sizes. The pigment is present in the glands of male and female animals. The 'delta' zone, as is to be expected, occasionally contains quantities of a black pigment which appears to be melanin.

It is impossible to observe the striking association of this pigment (presumably a carotene) with the adrenal of the opossum without coming to the conclusion that the adrenal must play an important rôle in the vitamin A metabolism in this animal. GEOFFrey BouRne.

(Hackett Research Student, University of Western Australia.)

From the Department of Anatomy,

University of Melbourne.

Arnold, J., Virch. Arch., 35, 64; 1866.

Bourne, G., NATURe, 131, 874, June 17, 1933.

Bourne, G., Aus. J. Exp. and Med. Sci., 12, in press.

\section{Alleged Stimulation of Moulds by Paraffin in Heavy Water}

IN a recent communication, Klar ${ }^{1}$ has questioned the results of experiments which seem to indicate that diplogen exerts a stimulative effect. He would attribute any such increase in growth as has been noted to the presence of organic impurity rather than to the heavy isotope of hydrogen. The investigations of Barnes ${ }^{2}$, Barnes and Larson ${ }^{3}$, Richards ${ }^{4}$, and Meyer ${ }^{5}$ have shown that such stimulation does occur and it has been attributed to the presence of the $\mathrm{D}$ atom. I was aware that there was a certain amount of inorganic, and possibly organic, impurity in the 'Ohio'-water used, approximately 0.04 per cent or less, but am of the opinion that the method of purifica. tion by a careful double- and triple-distillation in pyrex glassware removed any such impurity. The investigations reported here seem to substantiate this view.

After the double distillation of the 'Ohio'-water used in the experiments with Aspergillus sp., there was no detectable odour and the water had the 'flat' taste which is so characteristic of distilled $\mathrm{H}_{2} \mathrm{O}$. Approximately 25 c.c. of the 0.5 per cent deuterium oxide, twice-distilled, in each of four 125 c.c. Erlenmeyer flasks, left freely exposed in the laboratory for a period of 44 days, showed no growth of mould of any kind, whereas a solution of Pfeffer's three-salt and sucrose medium showed a heavy fungus growth within a week. If the organic impurity suggested by Klar were present in the heavy water, it was neither of a kind nor in sufficient quantity to serve as a nutrient for the growth of mould. Furthermore, the solution in which the Aspergillus sp. was grown, in the investigations reported, was Pfeffer's threesalt medium with sucrose as the source of carbon, a full nutrient solution for the growth of the fungus.
There was much more available organic compound present than the plants could possibly use in the five-day growth period. It seems exceedingly unlikely that this suggested organic impurity, if present, would have exerted so profound a stimulative effect in a medium already rich in available organic material.

Department of Biology, S. L. MEYER.

Vanderbilt University,

Nashville, Tennessee.

1 Klar, NATURE, 134, 104, July 21, 1934.

Barnes, $J$ Amer. Chem. Soc., 55, 4332; 1933. Amer. J. Bot., 20,679 ; 1933 . Science, 9,370 ; 1934.

133, 873, June 9, 1934.

. Bot., 20, 679; 1933. J. Bact., 28, 289; 1934 Science, 79, 210; 1934. J. Tenn. Acad. Sci., 9, No. 4 1934 (in press).

\section{Titration of Protein with Trichloroacetic Acid}

In a paper to the recent Faraday Society discussion on colloidal electrolytes, one of us (R.K. S.) pointed out that some of the difficulties encountered in the acid titration of proteins would be overcome by using an acid of which the anions become firmly bound to the positive groups of the protein. As a particular case, metaphosphoric acid was cited, the powerful coagulating power of which makes it a simple matter, after adding an excess of acid, to extract an aliquot free from protein for back titration.

We have just completed some preliminary trials with trichloroacetic acid, and find that edestine added to a 0.1 molar solution of this acid at the rate of about one gram per 100 c.c. and centrifuged, gives a clear liquid which contains only a trace of the added nitrogen and can be back-titrated to a sharp end. point. Similar results are obtained with the mixed proteins of wheat flour. The acid binding capacity of edestine determined in this way is in good agreement with published figures.

Trichloroacetic acid appears, therefore, to be a valuable reagent not only for the precipitation of protein, for which purpose its use in solutions of 10 per cent and upwards is already recognised, but also, when more dilute, for the rapid estimation of titratable amino-groups. Ordinary meta (glacial) phosphoric acid is a mixture of a number of acids of general formula $\left(\mathrm{HPO}_{3}\right)_{n}$, some of which are therefore polybasic. This introduces difficulties both in the back-titration and also in the interpretation of the results, so that this acid will probably prove to be less generally useful than trichloroacetic. The matter is being further investigated.

\section{R. Kenworthy Schofield.}

L. W. Samuel.

Rothamsted Experimental Station, Harpenden. Oct. 11.

\section{The Lobster, Enoplometopus occidentalis, Randall, in South Africa}

Recentuy Mr. E. C. Chubb, curator of the Durban Museum, sent for identification a very fine specimen of the above species. First recorded from Honolulu, the records of its occurrence have been proceeding westwards : Reunion (Milne Edwards), East Indies (de Man), and Mauritius (Bouvier). Its presence on the Natal coast is therefore not unexpected, but nevertheless interesting and worthy of record.

South African Museum, KePpel H. BarnaRd. Cape.Town. 